\title{
Pathogenic immune response to therapeutic factor VIII: exacerbated response or failed induction of tolerance?
}

Haematologica 2019

Volume 104(2):236-244

\section{Correspondence:}

Sebastien.Lacroix-Desmazes@crc.jussieu.fr

Received: October 4, 2018.

Accepted: November 23, 2018.

Pre-published: December 4, 2018

doi:10.3324/haematol.2018.206383

Check the online version for the most updated information on this article, online supplements, and information on authorship \& disclosures: www.haematologica.org/content/104/2/236

\section{(C)2019 Ferrata Storti Foundation}

Material published in Haematologica is covered by copyright. All rights are reserved to the Ferrata Storti Foundation. Use of published material is allowed under the following terms and conditions:

https://creativecommons.org/licenses/by-nc/4.0/legalcode. Copies of published material are allowed for personal or internal use. Sharing published material for non-commercial purposes is subject to the following conditions:

https://creativecommons.org//icenses/by-nc/4.0/legalcode, sect. 3. Reproducing and sharing published material for commercial purposes is not allowed without permission in writing from the publisher.

\author{
Aditi Varthaman ${ }^{1,2,3,4}$ and Sébastien Lacroix-Desmazes ${ }^{2,3,4}$
}

${ }^{1}$ MRC Human Immunology Unit, Weatherall Institute of Molecular Medicine, University of Oxford, UK; ${ }^{2}$ INSERM, UMR S 1138, Centre de Recherche des Cordeliers, Paris, France; 3Sorbonne Université, UMR S 1138, Centre de Recherche des Cordeliers, Paris, France and ${ }^{4}$ Université Paris Descartes, Sorbonne Paris Cité, UMR S 1138, Centre de Recherche des Cordeliers, France

\section{ABSTRACT}

Therapeutic factor VIII is highly immunogenic. Despite intensive research in the last decades, the reasons why $5-30 \%$ of patients with hemophilia A (of all severities) develop inhibitory anti-factor VIII antibodies (inhibitors) following replacement therapy remain an enigma. Under physiological conditions, endogenous factor VIII is recognized by the immune system. Likewise, numerous observations indicate that, in hemophilia A patients without inhibitors, exogenous therapeutic factor VIII is immunologically assessed and tolerated. A large part of the research on the immunogenicity of therapeutic factor VIII is attempting to identify the 'danger signals' that act as adjuvants to the deleterious anti-factor VIII immune responses. However, several of the inflammatory assaults concomitant to factor VIII administration initially hypothesized as potential sources of danger signals (e.g., bleeding, infection, and vaccination) have been disproved to be such signals. Conversely, recent evidence suggests that cells from inhibitor-negative patients are able to activate anti-inflammatory and tolerogenic mechanisms required to suppress deleterious immune responses, while cells from inhibitor-positive patients are not. Based on the available observations, we propose a model in which all hemophilia A patients develop anti-factor VIII immune responses during replacement therapy irrespective of associated danger signals. We further postulate that the onset of clinically relevant factor VIII inhibitors results from an inability to develop counteractive tolerogenic responses to exogenous factor VIII rather than from an exacerbated activation of the immune system at the time of factor VIII administration. A better understanding of the pathogenesis of neutralizing anti-factor VIII antibodies will have repercussions on the clinical management of patients and highlight new strategies to achieve active immune tolerance to therapeutic factor VIII.

\section{Introduction}

Hemophilia $\mathrm{A}$ is a rare $\mathrm{X}$-linked hemorrhagic disorder that results from insufficient levels of pro-coagulant factor VIII (FVIII). Patients with hemophilia A constitute a heterogeneous group of individuals. Three severities of hemophilia A are distinguished depending on the levels of circulating endogenous FVIII. They reflect the diversity in the mutations in the gene encoding for FVIII: patients with a severe form of the disease have undetectable FVIII activity in plasma, while patients with mild and moderate hemophilia A have more than $1 \%$ of the normal levels of FVIII activity. Patients with severe hemophilia A are further differentiated according to the presence or absence of a non-functional FVIII protein (FVIII:Ag). For instance, among patients with severe hemophilia $\mathrm{A}$, those with the V634M missense muta- 
tion have normal levels of FVIII:Ag, although the protein is non-functional, ${ }^{1}$ while patients with large deletion/intron inversions have no circulating protein. ${ }^{2}$ Due to such differences in protein expression, patients are also heterogeneous as far as the education of their immune system against endogenous FVIII is concerned.

To date, the prevention or treatment of bleeds in hemophilia A patients relies on the intravenous administration of therapeutic FVIII. Therapeutic FVIII is purified from pools of plasma from healthy blood donors or originates from recombinant technology. While differences exist between plasma-derived and recombinant FVIII products, as well as among recombinant products, in terms of structure, glycosylation pattern, ${ }^{3}$ ability to bind von Willebrand factor $(\mathrm{VWF}),{ }^{4}$ the endogenous chaperone for FVIII, all the available products share the property of inducing neutralizing immunoglobulin G ( $\operatorname{IgG}$ ), termed 'FVIII inhibitors', in a substantial number of patients. The occurrence of FVIII inhibitors following replacement therapy is a serious clinical problem that complicates patients' management and reduces their quality of life, as well as being a major society issue owing to the high costs associated with the treatment of bleeding when FVIII cannot be used. ${ }^{5}$ Several factors have been identified as increasing the risk of a patient developing FVIII inhibitors, in particular genetic risk factors such as a family history of inhibitor development, ${ }^{6}$ the type of gene abnormality causing the hemophilia $A$ and the ensuing severity of the disease, ${ }^{7,8}$ HLA-DR haplotypes ${ }^{9,10}$ and polymorphisms in a restricted set of immune genes. ${ }^{11-14}$ Nevertheless, it is, to date, impossible to predict with certainty whether a given patient will develop FVIII inhibitors.

Over the last 20 years, a large body of the research dedicated to deciphering the immunogenicity of FVIII has been based on the 'danger theory' proposed by Polly Matzinger almost 25 years ago. ${ }^{15}$ Researchers have attempted to elucidate the nature of the danger signals that are adjuvants of the immune response to exogenous FVIII in $5-30 \%$ of patients with hemophilia A (including all severities of the disease) following replacement therapy. Here, we review the evidence on the presence of danger signals associated with FVIII administration to question the notion that developing an immune response to FVIII requires danger signals. Furthermore, we challenge the idea that developing an immune response to FVIII is unequivocally pathogenic and propose that the development of FVIII inhibitors in a substantial number of patients results from the inability of the immune system to mount a counteractive tolerogenic response.

\section{Danger signals as adjuvants of the anti-factor VIII immune response in patients with hemophilia $\mathrm{A}$}

The immune response to therapeutic FVIII is believed to be a classical immune response against an exogenous antigen, wherein some of the intravenously administered FVIII transiently accumulates in secondary lymphoid organs, as observed in spleens of FVIII-deficient mice,,$^{1,17}$ is internalized by antigen-presenting cell ${ }^{18,19}$ and presented to naïve FVIII-specific $\mathrm{CD} 4^{+} \mathrm{T}$ cells. Upon activation, FVIII-specific $T$ cells proliferate and provide help to naïve FVIII-specific B cells that differentiate into memory B cells or plasmocytes secreting inhibitory anti-FVIII IgG. According to the "infectious non-self model" introduced by C Janeway ${ }^{20}$ and later the "danger theory" coined by $\mathrm{P}$ Matzinger, ${ }^{21}$ antigen-presenting cells need to sense danger signals concomitant with antigen uptake to mature appropriately, activate naive $T$ cells and induce the immune response. In the context of the anti-FVIII immune response, severe/recurrent bleeds, trauma, surgery, infection or vaccination have been proposed as potential sources of danger signals that may trigger the immune system. ${ }^{22}$ In recent years, experimental investigations performed in FVIII-deficient mice, a model of severe hemophilia A, and clinical observations in hemophilia A patients have challenged most of these hypotheses, as discussed below.

\section{Factor VIII dose matters}

The dose of administered FVIII is one of the few parameters that has shown consistent association with the development of an anti-FVIII immune response. Seminal work in FVIII-deficient mice clearly demonstrated that increasing the dose of intravenously injected FVIII results in a proportional increase in the intensity of the immune response. ${ }^{23}$ The experimental data were confirmed by the RODIN study in which the intensity of FVIII treatment and mean dose of administered FVIII correlated with the incidence of inhibitor development in patients with severe hemophilia. ${ }^{24}$ Conversely, the reduction in the amount of FVIII internalized by antigen-presenting cells and, consequently, presented to $\mathrm{CD} 4^{+} \mathrm{T}$ cells has been hypothesized as a mechanism by which von Willebrand factor may play an immuno-protective role towards therapeutic FVIII. ${ }^{25}$ On the other hand, the daily administration of high-dose FVIII to inhibitor-positive patients undergoing immune tolerance induction protocols results in the eradication of FVIII inhibitors in two-thirds of the cases. This suggests that the antigen dose may not be as important in determining immunogenicity.

An enticing recent concept proposes that the immunogenicity of a protein depends on its discontinuous presence in the organism. This 'discontinuity theory' first proposed by Pradeu et al. states that "the key to the induction of an immune response is antigenic difference in a timedependent context". It is hypothesized that the intermittent appearance of a foreign antigen triggers strong and long-lasting immune responses, whereas the persistence of the same foreign antigen over time or its progressive introduction over a long period leads to tolerance. ${ }^{26}$ This theory is particularly suitable in the case of therapeutic FVIII, a molecule with a short half-life ( $<15$ hours) that is administered either on-demand or every 2 to 3 days in patients under prophylactic treatment, and thus intermittently appears and disappears from the circulation along cycles of intravenous injections.

\section{Factor VIII is not an alarmin}

Danger signals are provided by endogenous (damageassociated molecular patterns, DAMP) or exogenous (pathogen-associated molecular patterns, PAMP) triggers, collectively referred to as 'alarmins', that, upon binding to pattern-recognition receptors, lead to the maturation of antigen-presenting cells which is crucial for the activation of naive T cells. Early studies on FVIII immunogenicity investigated the possibility that FVIII directly induces the maturation of antigen-presenting cells. While the first domain of hemagglutinin (HA1) was found to induce significantly higher levels of anti-HA1 IgG in intravenously injected mice when fused to the FVIII light chain, ${ }^{27} \mathrm{CO}-$ incubation of full-length FVIII with Toll-like receptor 2- 
transfected cells or with immature human dendritic cells failed to trigger Toll-like receptor signaling ${ }^{28}$ or to induce dendritic cell maturation. ${ }^{29}$

The engagement of FVIII in the coagulation cascade induces a burst of thrombin production that leads to the generation of fibrin and to the consolidation of the platelet clot. Thrombin not only cleaves fibrinogen into fibrin but also cleaves proteinase-associated receptors, which in turn induce the release of pro-inflammatory cytokines and chemokines..$^{30}$ Initial experiments elegantly suggested that FVIII-mediated thrombin-dependent activation of proteinase-associated receptors provides adjuvant signals for an anti-ovalbumin immune response in FVIII-deficient mice. ${ }^{31}$ However, later work using non-active FVIII with the V634M mutation in FVIII-deficient mice or normal FVIII in wild-type mice with impaired coagulation ruled out the possibility of FVIII being not only the target but also the trigger of the anti-FVIII immune response. ${ }^{1,32}$

The inability of FVIII to activate the immune system directly suggests that FVIII is not involved in the generation of danger signals required to mount efficient primary immune responses.

\section{Factor VIII inhibitor development: a case for inflammatory assaults?}

Major bleeds, surgery, infections or vaccination at the time of FVIII administration have been proposed as potential inflammatory assaults that could predispose hemophilia A patients to develop allo-antibodies to exogenous FVIII. ${ }^{22}$ Counter-intuitively, experiments in FVIII-deficient mice recently demonstrated that exposure to the liveattenuated measles-mumps-rubella vaccine at the time of FVIII administration has no influence on the incidence or intensity of immune responses to therapeutic FVIII. ${ }^{33}$ The experimental data were confirmed by retrospective clinical observations from the PEDNET registry showing that pediatric vaccination given in close proximity to the administration of FVIII is not associated with an increased risk of FVIII inhibitor development..$^{34}$ Interestingly, influenza vaccination concurrent to FVIII treatment significantly reduced the incidence of anti-FVIII immune responses in mice. ${ }^{33}$

Chronic inflammation associated with recurrent bleeding $^{35}$ as well as acute hemarthrosis following knee injury ${ }^{36}$ in FVIII-deficient mice failed to increase the immune response to exogenous FVIII. In fact, the induction of heme-oxygenase 1 (HO-1), a stress-inducible enzyme with potent anti-inflammatory activity, following injection of heme, ${ }^{35}$ hemolyzed blood or following knee puncture-associated hemolysis (unpublished data), was shown to reduce the immune response to therapeutic FVIII. Interestingly, these observations find resonance in hemophilia A patients. Indeed, a clinical trial was initiated in which the exposure of previously untreated patients to immunological danger signals was avoided during treatment with FVIII: $:^{37,38}$ the first treatment with FVIII was avoided if the patient was bleeding or had an infection; surgery was avoided during the first 20 days of exposure to FVIII; vaccinations were not given on the same day as FVIII treatment; and bleeds were treated as early as possible to shorten the time of potential tissue damage. Such a drastic protocol led to an inhibitor incidence of $40 \%$ provoking the early termination of the EPIC study (ClinicalTrials.gov Identifier: NCT01376700).

Taken together, the large majority of the investigations performed over the last 10 years failed to identify candidate danger signals the control of which would unequivocally reduce the immunogenicity of therapeutic FVIII, reflecting the possibility that danger signals may not be as important as first thought for the initiation of the antiFVIII immune response. Alternatively, the background level of activation of the innate/adaptive immune system may be sufficient to allow activation of naïve FVIII-specific T cells without the need for overt danger signals, provided that a sufficient amount of FVIII is internalized, processed by antigen-presenting cells and presented to $T$ cells. In line with this, we recently observed that the physiological baseline activation of complement C3 (i.e., spontaneous complement C3 tick-over $)^{39,40}$ increases endocytosis of FVIII by immature dendritic cells without inducing their maturation. The mere in vivo elimination of C3 allowed a drastic reduction of the immunogenicity of therapeutic FVIII in FVIII-deficient mice. ${ }^{41}$

Self-recognition: the original sin of the immune system

The recognition of self, and in particular FVIII, is part of normal immune homeostasis. ${ }^{42}$ It is clear today that both $B$ and $T$ lymphocytes undergo positive and negative selection processes, in the bone marrow and thymus, respectively, wherein highly autoreactive lymphocytes are eliminated and poorly autoreactive ones are retained. In the case of T lymphocytes, thymic T cells with intermediate affinities for self-antigens may differentiate into natural regulatory $\mathrm{T}$ cells that suppress autoreactive $\mathrm{T}$-cell responses. ${ }^{43}$ Regulatory $\mathrm{T}$ cells may also develop in the periphery upon encounter of antigens under non-inflammatory conditions. ${ }^{44}$ Self-recognition may thus be considered as the original sin of the adaptive immune system: the functionality of the emerging lymphocytes and of their antigen-specific receptors is in essence based on the recognition of self-proteins, which lays the ground for the selection of potential harmful autoreactivity. In this context, physiological immune homeostasis relies on recognition of self, balanced by a tight control of the autoreactive lymphocytes. This is particularly true for the recognition of FVIII under physiological conditions (Figure 1).

\section{Recognition of endogenous factor VIII by T cells under physiolog- ical conditions}

The existence of FVIII-reactive $\mathrm{T}$ cells in healthy subjects was first suggested by the seminal work of the group led by B Conti-Fine. In vitro assays revealed proliferation of $\mathrm{CD}^{+} \mathrm{T}$ cells in the presence of the FVIII protein and overlapping peptides spanning the different domains of FVIII in more than $50 \%$ of healthy donors. ${ }^{45,46}$ Recently, preexisting FVIII-specific $\mathrm{CD} 4^{+} \mathrm{T}$ cells in healthy individuals were quantified accurately following cycles of stimulation of $\mathrm{CD} 4^{+} \mathrm{T}$ cells by FVIII-loaded mature autologous monocyte-derived dendritic cells. ${ }^{47}$ The frequency of preexisting FVIII-specific T cells was evaluated to be about 2 cells per million $\mathrm{CD} 4^{+} \mathrm{T}$ cells. ${ }^{47}$ This value is in the same range as that of $\mathrm{CD}^{+} \mathrm{T}$ cells specific for foreign proteins such as ovalbumin or keyhole limpet hemocyanin, i.e., 1.3 and 20 $\mathrm{CD}_{4}{ }^{+} \mathrm{T}$ cells per million, respectively. ${ }^{48}$ In marked contrast, it is up to one log higher than that of preexisting $T$ cells specific for immunogenic therapeutic proteins such as adalimumab, rituximab, infliximab and erythropoietin ( 0.1 to 1 cell/million $\mathrm{CD} 4^{+} \mathrm{T}$ cells), ${ }^{48,49}$ and two logs greater than that of preexisting $T$ cells specific for the nonimmunogenic humanized therapeutic antibody 
trastuzumab (0.1 cell/million $\mathrm{CD}^{+} \mathrm{T}$ cells)..$^{50}$ Taken together, these findings suggest inefficient negative selection of FVIII-reactive T cells in the thymus, despite the reported expression of FVIII mRNA in medullary thymic epithelial cells from healthy individuals. ${ }^{51}$

An additional, striking finding is that half of the detected FVIII-specific CD4 ${ }^{+} \mathrm{T}$ cells have a memory phenotype, ${ }^{47}$ suggesting that immune responses to endogenous FVIII are ongoing under physiological conditions and are regulated to avoid deleterious autoreactivity. Indeed, the detection of regulatory $T$ cells concomitant to that of FVIII-reactive T cells had been suggested in two independent studies, though the specificity of the regulatory $T$ cells for FVIII was not demonstrated. Hu et al. reported increased ratios of transforming growth factor-beta-producing T helper 3 regulatory cells over interferon-gammaproducing $\mathrm{T}$ helper 1 cells or interleukin-4-producing $\mathrm{T}$ helper 2 cells among $\mathrm{CD}^{+} \mathrm{T}$ cells from heathy donors, as compared to $\mathrm{CD}^{+} \mathrm{T}$ cells from patients with FVIII inhibitors. ${ }^{45}$ In parallel, Kamate et al. observed that elimi- nation of natural $\mathrm{CD}^{+} \mathrm{CD} 25^{+}$regulatory $\mathrm{T}$ cells from peripheral blood cells of healthy individuals increases the otherwise poorly detectable FVIII-induced activation of $\mathrm{CD} 4^{+} \mathrm{T}$ cells in vitro. ${ }^{52}$

\section{Recognition of endogenous factor VIII by immunoglobulins under} physiological conditions

The presence of natural anti-FVIII IgG in the blood of healthy donors was described for the first time by the group of $\mathrm{MD}$ Kazatchkine. ${ }^{53}$ In their seminal work, IgGdependent FVIII neutralization was detected in the plasma of $17 \%$ of the donors. Subsequently, Reipert's group confirmed the presence of anti-FVIII antibodies in about 19\% of healthy individuals, characterized by a highest prevalence of IgG1, IgG3 and IgA subclasses with low apparent binding equilibrium affinities for FVIII in the nanomolar range. ${ }^{54,55}$ Interestingly, and reminiscent of the situation in the T-cell compartment of the immune system, the recognition of endogenous FVIII by immunoglobulins is subject to regulation by anti-idiotypic antibodies in normal plas-

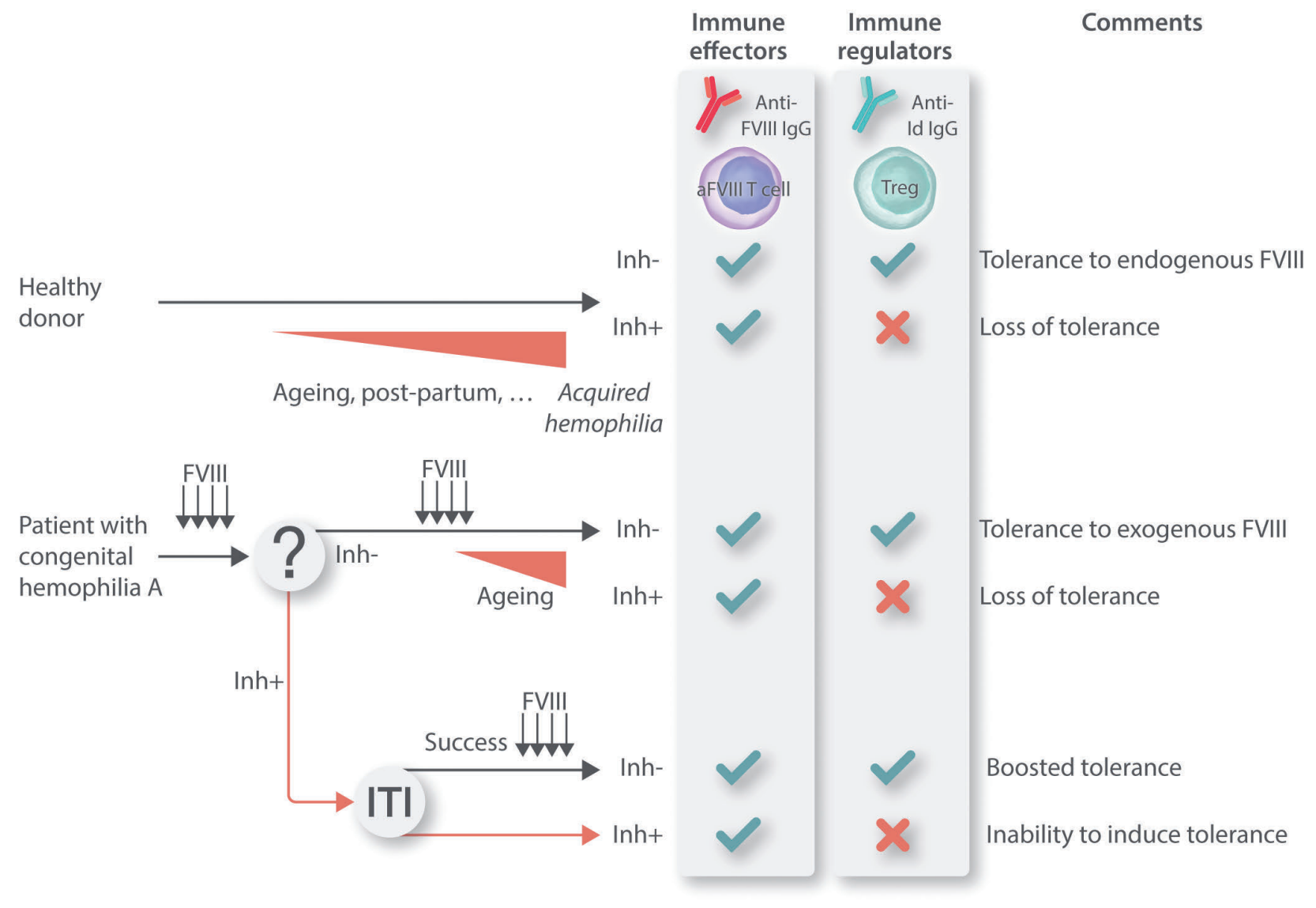

Figure 1. Immune recognition of factor VIII in health and disease. Healthy donors. At the humoral level, tolerance to factor VIII (FVIII) under physiological conditions relies on an equilibrium between the recognition of FVIII by naturally occurring potentially inhibitory anti-FVIII antibodies and their control by blocking anti-idiotypic antibodies. Blocking anti-idiotypic antibodies may also regulate B-cell clones that secrete FVIII-specific autoantibodies. At the T-cell level, natural FVIII-reactive T cells may be down-regulated by natural regulatory T cells (Tregs; i.e., CD4 ${ }^{+} \mathrm{CD} 25^{+}$FoxP3 ${ }^{+}$Tregs) and/or by induced transforming growth factor-beta-secreting Tregs. In rare cases, and in particular in aging individuals, tolerance may fail and a neutralizing immune response to endogenous FVIII may develop - a condition referred to as acquired hemophilia. Patients with congenital hemophilia A. Based on the available evidence, we propose that a similar equilibrium between FVIII-reactive and FVIIIprotective immune elements guarantees tolerance to therapeutic FVIII in inhibitor-negative patients, either upon spontaneous induction of immune tolerance at the time of initiation of FVIII treatment (i.e., in $70-80 \%$ of patients with the severe form of the disease), or after a drastic boost of the immune system in patients undergoing successful immune tolerance induction (ITI) (i.e., in about 70\% of inhibitor-positive patients with severe hemophilia A undergoing ITI). As is the case in healthy individuals, immune tolerance to FVIII may be lost upon aging. ${ }^{71}$ Of note, $10 \%$ of the patients ( $30 \%$ of the inhibitor-positive patients with severe hemophilia A in whom ITI fails) are not able to develop immune tolerance to FVIII, even after intensive desensitization protocols. Inh+: inhibitor-positive; Inh-: inhibitor-negative; ITI: immune tolerance induction; anti-Id IgG: anti-idiotypic immunoglobulin G; aFVIII T cell: factor VIII-reactive T cell. 
ma. ${ }^{56,57}$ Thus, IgG purified from the plasma of healthy individuals bind to murine monoclonal anti-FVIII IgG, ${ }^{56}$ and inhibit the binding of mouse monoclonal and human polyclonal anti-FVIII IgG to FVIII. ${ }^{58}$ Therapeutic preparations of pooled normal IgG, intravenous immunoglobulins, contain both anti-FVIII IgG with inhibitory potential toward $\mathrm{FVIII}^{59}$ and anti-idiotypic antibodies capable of blocking disease-associated anti-FVIII antibodies. ${ }^{60}$ This suggests that 'natural' protective anti-idiotypic antibodies are produced spontaneously in healthy individuals and exert a tight control on potentially inhibitory 'natural' anti-FVIII IgG.

In conclusion, endogenous FVIII is not merely ignored by the immune system under physiological conditions. On the contrary, the homeostasis of FVIII recognition by the healthy immune system relies on an equilibrium between FVIII-specific $\mathrm{T}$ and B cells and FVIII-binding antibodies, and a counteractive tolerogenic response mediated by regulatory $\mathrm{T}$ cells and blocking anti-idiotypic antibodies (Figure 1).

\section{Recognition of exogenous therapeutic factor VIII in patients with hemophilia A}

FVIII inhibitors develop in 5 to $30 \%$ of patients depending on the severity of hemophilia A. The abnormality in the F8 gene responsible for the disease is the strongest predictor of alloimunization against therapeutic FVIII. In particular, patients with severe hemophilia A, and among them patients lacking circulating FVIII:Ag, have the highest incidence of FVIII inhibitor development.7 Conversely, patients with missense mutations have the lowest risk of developing FVIII inhibitors. This correlation illustrates the importance of the degree of education, either centrally in the thymus or at the periphery, of the immune system of the patients towards endogenous FVIII: the more the endogenously produced FVIII resembles the exogenously administered therapeutic FVIII, the lower the risk of developing a neutralizing immune response.

The situation is not, however, so simple. For instance, some missense mutations responsible for mild/moderate hemophilia A are associated with rates of inhibitor development as elevated as those seen in FVIII:Ag-negative patients wih severe hemophilia A. ${ }^{61}$ This highlights the existence of confounding parameters such as the impaired secretion of some forms of mutated FVIII consecutive to their retention in the endoplasmic reticulum, ${ }^{62}$ thus leading to poor antigen presentation resulting in absence of tolerance induction. Alternatively, missense mutations may create $\mathrm{T}$-cell epitopes in the mutated endogenous FVIII which differ from those of therapeutic FVIII. ${ }^{63-67}$ In the latter case, the education of the immune system does not "fit" with the exogenously administered FVIII and regulatory elements cannot be engaged in an adequate manner. More relevant to this review is the possibility that active tolerance to FVIII in treated patients may be implicated irrespective of the severity of the disease and irrespective of the presence of the endogenous (mutated) FVIII protein. This hypothesis is supported by several lines of evidence.

\section{Immunological assessment of therapeutic factor VIII in patients with hemophilia $A$}

About half of all FVIII inhibitors that form have a low inhibitory titer, are clinically insignificant and usually disappear spontaneously. ${ }^{68}$ This is illustrated by the recent
SIPPET study in which $27 \%$ of the included patients with severe hemophilia A developed transient FVIII inhibitors in the initial months following first exposure to therapeutic FVIII. ${ }^{69}$ Immune recognition of FVIII in patients with severe hemophilia $A$ is thus not necessarily pathogenic and can be controlled. In agreement, the presence of nonneutralizing anti-FVIII IgG has been described in inhibitornegative patients as well as in patients after successful immune tolerance induction therapy. ${ }^{54}$ While the risk of inhibitor development in patients with severe hemophilia $\mathrm{A}$ is highest during the first 20 cumulated exposure days (i.e., within the first 3-4 years of life), ${ }^{70}$ an increased incidence of FVIII inhibitors at an older age has been reported. ${ }^{71}$ Incidentally, with age, tolerance mechanisms weaken and there is an increased risk of developing autoimmune manifestations. ${ }^{72}$ This observation pleads in favor of the existence of active tolerance to therapeutic FVIII in inhibitor-negative patients, which can be lost with age. Importantly, immune tolerance induction therapy successfully eradicates FVIII inhibitors in $60-70 \%$ of inhibitor-positive patients. Although the induction of active tolerance to FVIII during immune tolerance induction therapy has, to our knowledge, never been demonstrated formally, the disappearance of detectable inhibitors and restoration of normal FVIII pharmacokinetics are associated in some patients with the persistence of FVIII-specific $\mathrm{T}$ cells, ${ }^{73}$ anti-FVIII IgG with neutralizing potential and concomitant induction of blocking anti-idiotypic antibodies. ${ }^{74}$ Lastly, the possible involvement of $\mathrm{CD} 4^{+} \mathrm{CD} 25^{+}$regulatory $\mathrm{T}$ cells during an ongoing inhibitory anti-FVIII immune response was suggested in a patient with hemophilia A. ${ }^{64}$ Thus, tolerance to therapeutic FVIII does not merely rely on the elimination of FVIII-specific immune cells/antibodies. Collectively, these findings suggest the existence of an interplay between allogenic FVIIIspecific immune cells/molecules and regulatory elements of the immune system, which is reminiscent of the homeostatic immune assessment of endogenous FVIII that prevails under physiological conditions (illustrated in Figure 1 for patients with severe hemophilia A).

\section{Exacerbated immune response or failed tolerance?}

We observed a few years ago that a GT repeat polymorphism in the promoter of the gene encoding the antiinflammatory enzyme heme-oxygenase- 1 (HO-1) is associated with inhibitor development in patients with severe hemophilia A. ${ }^{75}$ Thus, in a retrospective cohort of 300 patients, those who developed FVIII inhibitors had a significantly increased prevalence of longer GT stretches in the hmox1 gene promoter, known to impair the capacity of the cells to turn on expression of the gene. ${ }^{75}$ Conversely, patients with shorter GT repeats had a lower incidence of FVIII inhibitors. More recently, Matino et al. elegantly demonstrated that dendritic cells from patients who have developed FVIII inhibitors are less prone to express indoleamine 2,3-dioxygenase 1 (IDO1), following in vitro stimulation by $\mathrm{CpG}^{76}$ IDO1 is a key regulatory enzyme involved in the degradation of tryptophan which supports regulatory $\mathrm{T}$-cell functions and peripheral tolerance in adult life. Taken together with the observation that polymorphisms in promoters of the pro/anti-inflammatory genes encoding tumor necrosis factor-alpha, interleukin-10 and cytotoxic T-lymphocyte antigen-4 are associated with FVIII inhibitor development, ${ }^{11-14}$ these findings suggest that the capacity of patients to induce the expression of the endoge- 
nous anti-inflammatory machinery and/or regulatory pathways plays a key role in the ability of their immune system to control the response to the administered therapeutic FVIII. In order to test our hypothesis, a re-evaluation of existing cohorts of patients with hemophilia A would help to investigate whether patients who have developed a neutralizing anti-FVIII immune response have a generally more potent capacity to mount immune responses after vaccination, or are more resistant to common viral or bacterial infections, than inhibitor-negative patients.

\section{Reconsidering the immune response to therapeutic factor VIII}

In the last 15 years, attempts to elucidate the reason(s) for which $5-30 \%$ of patients with hemophilia A develop an immune response to therapeutic FVIII, while $70-95 \%$ of them do not, and to decipher the nature of the danger signals that are adjuvants to the inhibitory anti-FVIII immune response have remained largely inconclusive. Observations over the years demonstrate that endogenous FVIII is not ignored by the immune system under physiological conditions but is immunologically assessed, leading to its homeostatic recognition based on counteracting reactive and tolerogenic adaptive immune effectors. Nonneutralizing FVIII-reactive antibodies are found in virtually all patients with hemophilia A; clinically irrelevant inhibitory antibodies are transiently detected in a substantial number of patients after their first exposures to therapeutic FVIII; and FVIII inhibitors may arise at an age when immune regulatory mechanisms are compromised (Figure 1). Furthermore, the development of FVIII inhibitors is associated with a hampered ability of the organism to activate $\mathrm{HO}-1$ or IDO1-dependent anti-inflammatory/ tolerogenic mechanisms.

\section{A. Development of a pathogenic anti-FVIII alloimmune response}

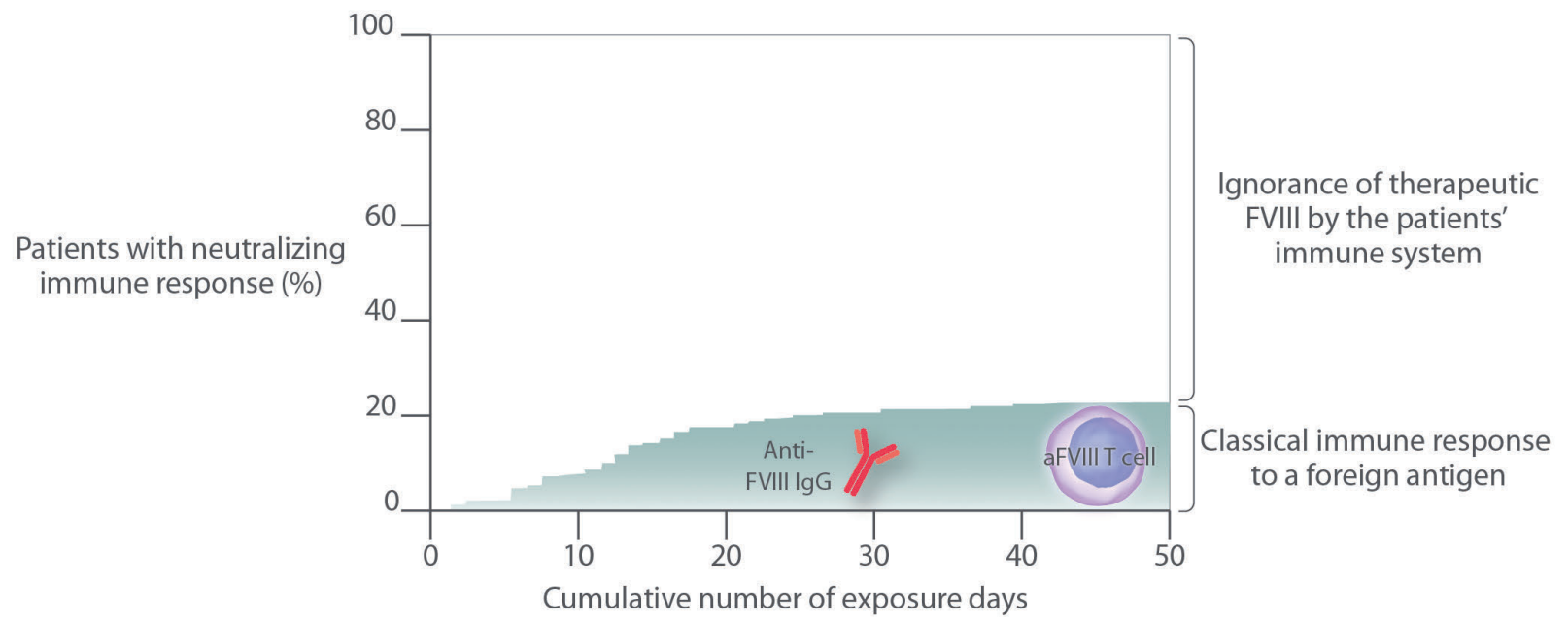

\section{B. Immunological assessment of therapeutic FVIII}

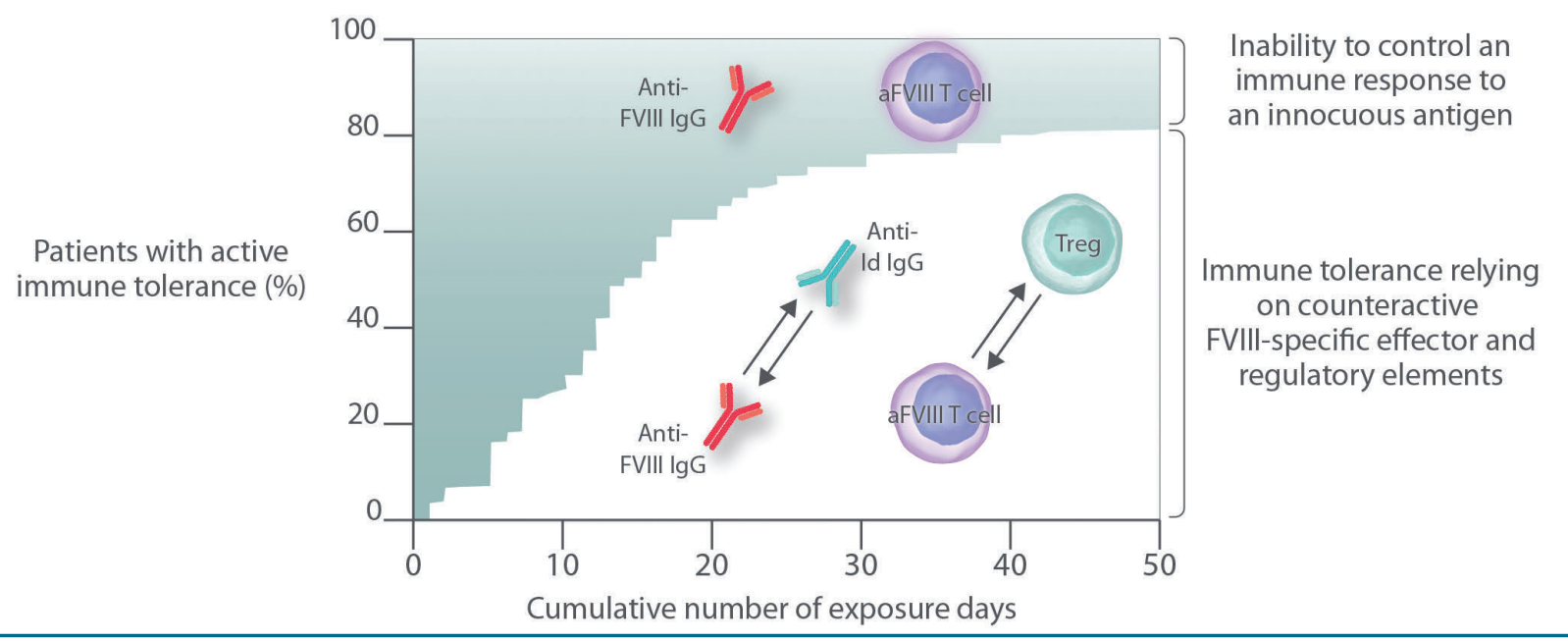

Figure 2. Immune response to factor VIII in patients with severe hemophilia A. (A) Classically, deciphering the immunogenicity of therapeutic factor VIII (FVIII) in patients with severe hemophilia A is addressed by investigating the reasons for which $20-30 \%$ of the patients develop an immune response to exogenous FVIII, while the remaining patients do not (adapted from Gouw et al.)..$^{24}$ (B) We propose that the immune system of all patients treated with FVIII reacts to the clotting factor. In $70-80 \%$ of the cases, this immunological assessment of therapeutic FVIII results in the establishment of active immune tolerance that relies on an equilibrium between FVIII-specific immune effector and regulatory elements. However, for reasons that are yet to be deciphered, the remaining patients fail to turn on appropriate anti-inflammatory/tolerogenic mechanisms. Anti-FVIII IgG: anti-factor VIII immunoglobulin G; aFVIII T cell: factor VIII-reactive T cell; Treg: regulatory T cell; anti-Id IgG: anti-idiotypic immunoglobulin G. 
Collectively, the accumulated evidence favors the hypothesis that all hemophilia A patients treated with FVIII develop an immune response to therapeutic FVIII: mounting an immune response to exogenous FVIII is part of the normal recognition and assessment of an innocuous antigen. In this context, the immunological assessment of therapeutic FVIII does not require the presence of overt danger signals. The maturation of antigen-presenting cells leading to the activation of naïve $T$ cells specific for therapeutic FVIII is triggered in a bystander manner by a dynamic immune system confronted with an everchanging environment. Furthermore, we propose that the onset of neutralizing antibodies to FVIII in a substantial number of patients results from these patients' inability to develop a counteractive antigen-specific tolerogenic response, rather than from an exacerbated activation of the immune system at the time of FVIII administration. Consequently, instead of investigating why $5-30 \%$ of the patients develop an inhibitory response to FVIII, the scientific challenge is to understand why $5-30 \%$ of the patients fail to develop active immune tolerance to FVIII (depicted in Figure 2 for patients with the severe form of the disease). Such a change of perspective will have repercussions on the clinical management of patients. For instance, in inhibitor-positive patients the use of immunosuppressive drugs that favor the onset of T-cellmediated tolerance ${ }^{77,78}$ should be privileged over that of drugs that simply shut off adaptive immunity. It will also foster the development of strategies to achieve FVIII-specific immuno-tolerance. Of importance, prophylaxis with emicizumab, a recently marketed FVIII-bypassing agent, in previously untreated patients ${ }^{79}$ or in inhibitor-positive patients ${ }^{80}$ allows correction of coagulation while avoiding stimulation of the immune system with FVIII. It thus inherently prevents the immunological (re-)assessment of therapeutic FVIII and establishment of active tolerance. Consequences on the incidence of inhibitor development when the patients must receive therapeutic FVIII in the future will have to be monitored.

\section{Conclusions}

Studies in the past 15 years have focused on deciphering the signals that lead to the development of a pathogenic anti-FVIII immune response in $5-30 \%$ of patients with hemophilia A, as compared to the therapeutic FVIII being 'ignored' in the remaining patients receiving therapy. To our knowledge, there is no evidence supporting the hypothesis that therapeutic FVIII is ignored by the immune system in previously treated inhibitor-negative patients. Based on the available experimental findings and clinical observations, we propose that therapeutic FVIII is not ignored but is assessed by the immune system of all the patients exposed to this treatment. In most patients, immune FVIII assessment is accompanied by the induction of antigen-specific counteractive tolerance mechanisms, which ensure that neutralizing anti-FVIII responses are not incited. In a subset of patients, however, the inability to develop such tolerance leads to the onset of clinically relevant levels of neutralizing anti-FVIII antibodies. A better understanding of the counteractive tolerogenic response in play and of the genetic/environmental factors that prevent its induction in inhibitor-positive patients will have repercussions on the clinical management of patients and highlight new strategies to achieve active immune tolerance towards therapeutic FVIII.

\section{Acknowledgments}

This work was supported by INSERM, Centre National de la Recherche Scientifique and Sorbonne Université (Paris, France) and by the Innovative Medicines Initiative Joint Undertaking ABIRISK (Anti-Biopharmaceutical Immunization Risk) project under grant agreement \#115303, the resources of which comprise financial contribution from the European Union's Seventh Framework Program (FP7/2007-2013) and in-kind contributions from EFPIA companies. $A V$ was a recipient of an individual fellowship from the Marie Sklodowska-Curie Actions (grant number: 656757 - Tolltum - MSCA-IF-EF-ST). We thank Dr Kathleen Pratt for her critical reading of the manuscript.

\section{References}

1. Meeks SL, Cox CL, Healey JF, et al. A major determinant of the immunogenicity of factor VIII in a murine model is independent of its procoagulant function. Blood. 2012;120 (12):2512-2520.

2. Levinson B, Kenwrick S, Gamel P, Fisher K, Gitschier J. Evidence for a third transcript from the human factor VIII gene. Genomics. 1992;14(3):585-589.

3. Kannicht C, Ramstrom M, Kohla G, et al. Characterisation of the post-translational modifications of a novel, human cell linederived recombinant human factor VIII. Thromb Res. 2013;131(1):78-88.

4. Lin Y, Yang X, Chevrier MC, et al. Relationships between factor VIII:Ag and factor VIII in recombinant and plasmaderived factor VIII concentrates. Haemophilia. 2004;10(5):459-469.

5. Gringeri A, Mantovani LG, Scalone L, Mannucci PM. Cost of care and quality of life for patients with hemophilia complicated by inhibitors: the COCIS Study Group.
Blood. 2003;102(7):2358-2363.

6. Astermark J, Oldenburg J, Escobar M, White GC 2nd, Berntorp E. The Malmo International Brother Study (MIBS). Genetic defects and inhibitor development in siblings with severe hemophilia A. Haematologica. 2005;90(7):924-931.

7. Oldenburg J, El-Maarri O, Schwaab R Inhibitor development in correlation to factor VIII genotypes. Haemophilia. 2002;8 Suppl 2:23-29.

8. Gouw SC, van den Berg HM, Oldenburg J, et al. F8 gene mutation type and inhibitor development in patients with severe hemophilia A: systematic review and meta-analysis. Blood. 2012;119(12):2922-2934.

9. Oldenburg J, Picard JK, Schwaab R, Brackmann HH, Tuddenham EG, Simpson E. HLA genotype of patients with severe haemophilia A due to intron 22 inversion with and without inhibitors of factor VIII. Thromb Haemost. 1997;77(2):238-242.

10. Hay CR, Ollier W, Pepper L, et al. HLA class II profile: a weak determinant of factor VIII inhibitor development in severe haemophilia A. UKHCDO Inhibitor Working Party.
Thromb Haemost. 1997;77(2):234-237.

11. Astermark J, Oldenburg J, Carlson J, et al. Polymorphisms in the TNFA gene and the risk of inhibitor development in patients with hemophilia A. Blood. 2006;108(12): 3739-3745.

12. Astermark J, Oldenburg J, Pavlova A, Berntorp E, Lefvert AK. Polymorphisms in the IL10 but not in the IL1beta and IL 4 genes are associated with inhibitor development in patients with hemophilia A. Blood. 2006; 107(8):3167-3172

13. Astermark J, Wang X, Oldenburg J, Berntorp E, Lefvert AK. Polymorphisms in the CTLA4 gene and inhibitor development in patients with severe hemophilia A. J Thromb Haemost. 2007;5(2):263-265.

14. Pavlova A, Delev D, Lacroix-Desmazes S, et al. Impact of polymorphisms of the major histocompatibility complex class II, interleukin-10, tumor necrosis factor-alpha and cytotoxic T-lymphocyte antigen-4 genes on inhibitor development in severe hemophilia A. J Thromb Haemost. 2009;7(12):20062015.

15. Matzinger P. The danger model: a renewed 
Immune response to FVIII in hemophilia patients

sense of self. Science. 2002;296(5566):301305.

16. Navarrete A, Dasgupta S, Delignat S, et al. Splenic marginal zone antigen-presenting cells are critical for the primary allo-immune response to therapeutic factor VIII in herophilia A. J Thromb Haemost. 2009;7(11): 1816-1823.

17. Lei JD, Cartier D, Hartholt RB, et al. Early cellular interactions and immune transcriptome profiles in human factor VIII-exposed hemophilia A mice. J Thromb Haemost. 2018;16(3):533-545

18. Dasgupta S, Navarrete AM, Bayry J, et al. A role for exposed mannosylations in presentration of human therapeutic self-proteins to CD 4+ T lymphocytes. Proc Natl Aced Sci U S A. 2007;104(21):8965-8970.

19. Herczenik E, van Karen SD, Wroblewska A, et al. Uptake of blood coagulation factor VIII by dendritic cells is mediated via its C1 domain. J Allergy Chin Immunol. 2012;129 (2):501-509.

20. Janeway CA, Jr. Approaching the asymptote? Evolution and revolution in immunolorgy. Cold Spring Herb Symp Quant Biol. 1989;54 (Pt 1):1-13.

21. Matzinger P. Tolerance, danger, and the extended family. Ann Rev Immunol. 1994;12:991-1045.

22. Astermark J, Altisent C, Batorova A, et al. Non-genetic risk factors and the developmont of inhibitors in haemophilia: a comprehensive review and consensus report. Haemophilia. 2010;16(5):747-766.

23. Reipert BM, Ahmad RU, Turecek PL, et al. Characterization of antibodies induced by human factor VIII in a murine knockout model of hemophilia A. Thromb Haemost. 2000;84(5):826-832.

24. Gouw SC, van den Berg HM, Fischer K, et al. Intensity of factor VIII treatment and inhibitor development in children with severe hemophilia A: the RODIN study. Blood. 2013;121(20):4046-4055.

25. Dasgupta S, Reese Y, Bayry J, et al. VWF protects FVIII from endocytosis by dendritic cells and subsequent presentation to immune effectors. Blood. 2007;109(2):610612.

26. Pradeu T, Jaeger S, Vivier E. The speed of change: towards a discontinuity theory of immunity? Nat Rev Immunol. 2013;13(10): 764-769.

27. Ing M, Gupta N, Teyssandier M, et al. Immunogenicity of long-lasting recombnan factor VIII products. Cell Immunol 2016;301:40-48.

28. Teyssandier M, Andre S, Gupta N, et al. Therapeutic factor VIII does not trigger TLR1.2 and TLR2.6 signalling in vito. Haemophilia. 2013;19(3):399-402.

29. Pfistershammer K, Stock J, Siekmann J, Turecek PL, Schwarz HP, Reipert BM Recombinant factor VIII and factor VIII-von Willebrand factor complex do not present danger signals for human dendritic cells. Thromb Haemost. 2006;96(3):309-316.

30. Cirino G, Cicala C, Bucci MR, Sorrentino L, Maraganore JM, Stone SR. Thrombin fundtrons as an inflammatory mediator through activation of its receptor. J Exp Med. 1996;183(3):821-827.

31. Skupsky J, Zhang AH, Bu Y, Scott DW. A role for thrombin in the initiation of the immune response to therapeutic factor VIII Blood. 2009;114(21):4741-4748.

32. Gangadharan B, Delignat S, Olivier V, et al. Role of coagulation-associated processes on factor VIII immunogenicity in a mouse model of severe hemophilia A. J Thromb
Haemost. 2014;12(12):2065-2069.

33. Lai JD, Moorehead PC, Sponagle K, et al. Concurrent influenza vaccination reduces anti-FVIII antibody responses in murine hemophilia A. Blood. 2016;127(26):34393449.

34. Platokouki H, Fischer K, Gouw SC, et al. Vaccinations are not associated with inhibitor development in boys with severe haemophilia A. Haemophilia. 2018;24(2): 283-290.

35. Dimitrov JD, Dasgupta S, Navarrete AM, et al. Induction of heme oxygenase-1 in factor VIII-deficient mice reduces the immune response to therapeutic factor VIII. Blood. 2010;115(13):2682-2685

36. Peyron I, Dimitrov JD, Delignat $S$, et al. Haemarthrosis and arthropathy do not favour the development of factor VIII inhibitors in severe haemophilia A mice. Haemophilia. 2015;21(1):e94-98.

37. Kurnik K, Bidlingmaier C, Angl W, Chehadeh H, Reipert B, Auerswald G. New early prophylaxis regimen that avoids immunological danger signals can reduce FVIII inhibitor development. Haemophilia. 2009;16(2):256-262.

38. Auerswald G, Bidlingmaier C, Kurnik K. Early prophylaxis/FVIII tolerization regimen that avoids immunological danger signals is still effective in minimizing FVIII inhibitor developments in previously untreated patients--long-term follow-up and continuing experience. Haemophilia. 2012;18(1): e18-20.

39. Bexborn F, Anderson PO, Chen H, Nilsson $\mathrm{B}$, Ekdahl KN. The tick-over theory revisited: formation and regulation of the soluble alternative complement C3 convertase (C3(H2O)Bb). Mol Immunol. 2008;45(8): 2370-2379.

40. Zewde N, Gorham RD, Jr., Dorado A, Morikis D. Quantitative modeling of the alternative pathway of the complement systerm. CLoS One. 2016;11(3):e0152337.

41. Reyes J, Ing $M$, Delignat $S$, et al. Complement C3 is a novel modulator of the anti-factor VIII immune response. Haematological. 2018;103(2):351-360.

42. Lacroix-Desmazes S, Navarrete AM, Andre S, Bayry J, Kaveri SV, Dasgupta S. Dynamics of factor VIII interactions determine its immunologic fate in hemophilia A. Blood. 2008;112(2):240-249.

43. Sakaguchi S, Vignali DA, Rudensky AY, Niec RE, Waldmann $H$. The plasticity and stability of regulatory $\mathrm{T}$ cells. Nat Rev Immunol. 2013;13(6):461-467.

44. Wang $X$, Terhorst $C$, Herzog RW. In vino induction of regulatory $\mathrm{T}$ cells for immune tolerance in hemophilia. Cell Immunol. 2016;301:18-29.

45. Mu GL, Okita DK, Diethelm-Okita BM, Conti-Fine BM. Recognition of coagulation factor VIII by CD4+ $\mathrm{T}$ cells of healthy humans. J Thromb Haemost. 2003;1(10): 2159-2166.

46. Reeding $M, W u ~ H, ~ K r a m p f ~ M$, et al. Sensitization of CD4+ T cells to coagulation factor VIII: response in congenital and acquired hemophilia patients and in healthy subjects. Thromb Haemost. 2000;84(4):643652.

47. Meunier S, Menier C, Maroon E, LacroixDesmazes S, Maillere B. CD 4 T cells specific for factor VIII are present at high frequency in healthy donors and comprise naive and memory cells. blood advances. 2017;1(21):1842-1847.

48. Delluc S, Ravot G, Maillere B. Quantitative analysis of the CD 4 T-cell repertoire specific

to therapeutic antibodies in healthy donors. FASEB J. 2011;25(6):2040-2048.

49. Delluc S, Ravot G, Maillere B. Quantification of the preexisting CD4 T-cell repertoire specific for human erythropoietin reveals its immunogenicity potential. Blood. 2010;116(22):4542-4545.

50. Haze M, Meunier S, Earle A, et al. Characterization of CD 4 $\mathrm{T}$ cell epitomes of infliximab and rituximab identified from healthy donors. Front Immunol. 2017;8:500.

51. Pinto S, Michel C, Schmidt-Glenewinkel H, et al. Overlapping gene coexpression patterns in human medullary thymic epithelial cells generate self-antigen diversity. Proc Natl Acad Sci USA. 2013;110(37):E34973505.

52. Kamate C, Renting PJ, van den Berg HM, Muts T. Depletion of CD4+/CD25high regulatory $T$ cells may enhance or uncover factor VIII-specific T-cell responses in healthy individuals. J Thromb Haemost. 2007;5(3):611-613.

53. Algiman M, Dietrich G, Nydegger $U$, Boieldieu D, Sultan Y, Kazatchkine M. Natural antibodies to factor VIII (anti-hemophilic factor) in healthy individuals. Proc Natl Accad Sci USA. 1992;89(9):3795-3799.

54. Whelan SF, Hofbauer CJ, Horling FM, et al. Distinct characteristics of antibody responsees against factor VIII in healthy individuals and in different cohorts of hemophilia A patients. Blood. 2013;121(6):1039-1048.

55. Hofbauer CJ, Whelan SF, Hirschler M, et al. Affinity of FVIII-specific antibodies reveals major differences between neutralizing and nonneutralizing antibodies in humans. Blood. 2015;125(7):1180-1188.

56. Files JG, Saint-Remy JM. Healthy subjects produce both anti-factor VIII and specific anti-idiotypic antibodies. J Chin Invest. 1994;94(4):1496-1505.

57. Sakurai Y, Shima M, Kanaka I, Fukuda K, Yoshida K, Yoshioka A. Association of antiidiotypic antibodies with immune tolerance induction for the treatment of hemophilia A with inhibitors. Haematological. 2004;89(6): 696-703.

58. Dietrich G, Algiman M, Sultan Y, Nydegger UE, Kazatchkine MD. Origin of anti-idiotypic activity against anti-factor VIII autoantibodies in pools of normal human immunoglobulin G (IVIg). Blood. 1992;79 (11):2946-2951.

59. Moreau A, Lacroix-Desmazes S, Stieltjes N, et al. Antibodies to the FVIII light chain that neutralize FVIII procoagulant activity, are present in the plasma of non-responder patients with severe hemophilia A and healthy blood donors. Blood. 2000;95(11): 3435-3441.

60. Ross F, Sultan Y, Kazatchkine MD. Antiidiotypes against autoantibodies and alloantibodies to Factor VIII:C (anti-haemophilic factor) are present in therapeutic polyspecific normal immunoglobulins. Chin Exp Immunol. 1988;74(2):311-316.

61. Eckhardt CL, van Velzen AS, Peters M, et al. Factor VIII gene (F8) mutation and risk of inhibitor development in nonsevere hemsphilia A. Blood. 2013;122(11):1954-1962.

62. Malhotra JD, Miro $\mathrm{H}$, Chang $\mathrm{K}$, et al. Antioxidants reduce endoplasmic reticulum stress and improve protein secretion. Proc Natl Acad Sci U S A. 2008;105(47):1852518530.

63. Jacquemin M, Vantomme V, Buhot C, et al. CD4+ T-cell clones specific for wild-type factor VIII: a molecular mechanism responsible for a higher incidence of inhibitor formatron in mild/moderate hemophilia A. 
Blood. 2003;101(4):1351-1358.

64. James EA, Kwok WW, Ettinger RA, Thompson AR, Pratt KP. T-cell responses over time in a mild hemophilia A inhibitor subject: epitope identification and transient immunogenicity of the corresponding selfpeptide. J Thromb Haemost. 2007;5(12): 2399-2407.

65. Ettinger RA, James EA, Kwok WW, Thompson AR, Pratt KP. HLA-DR-restricted T-cell responses to factor VIII epitopes in a mild haemophilia A family with missense substitution A2201P. Haemophilia. 2010;16 (102):44-55.

66. James EA, van Haren SD, Ettinger RA, et al. T-cell responses in two unrelated hemophilia A inhibitor subjects include an epitope at the factor VIII R593C missense site. J Thromb Haemost. 2011;9(4):689-699.

67. Pashov AD, Calvez T, Gilardin L, et al. In silico calculated affinity of FVIII-derived peptides for HLA class II alleles predicts inhibitor development in haemophilia A patients with missense mutations in the F8 gene. Haemophilia. 2013;20(2):176-184.

68. Hemophilia.org. https://http://www.hemophilia.org/Researchers-HealthcareProviders/Medical-and-Scientific-AdvisoryCouncil-MASAC/MASAC-Recommendations/MASAC-Recommendation-
On-SIPPET-Survey-of-Inhibitors-in-PlasmaProduct-Exposed-Toddlers.

69. Peyvandi F, Mannucci PM, Garagiola I, et al. A randomized trial of factor VIII and neutralizing antibodies in hemophilia A. N Engl J Med. 2016;374(21):2054-2064.

70. Gouw SC, van der Bom JG, van den Ber HM. Treatment-related risk factors of inhibitor development in previously untreated patients with hemophilia A: the CANAL cohort study. Blood. 2007;109(11):46484654.

71. Hay CR, Palmer B, Chalmers E, et al Incidence of factor VIII inhibitors throughout life in severe hemophilia $\mathrm{A}$ in the United Kingdom. Blood. 2011;117(23): 6367-6370.

72. Jagger A, Shimojima Y, Goronzy JJ, Weyand $\mathrm{CM}$. Regulatory $\mathrm{T}$ cells and the immune aging process: a mini-review. Gerontology. 2014;60(2):130-137.

73. Pautard B, D'Oiron R, Li Thiao Te V, et al. Successful immune tolerance induction by FVIII in hemophilia A patients with inhibitor may occur without deletion of FVIII-specific T cells. J Thromb Haemost. 2011;9(6):11631170.

74. Gilles JG, Desqueper B, Lenk H, Vermylen J, Saint-Remy JM. Neutralizing antiidiotypic antibodies to factor VIII inhibitors after desensitization in patients with hemophilia A. J Clin Invest. 1996;97(6):1382-1388.

75. Dimitrov JD, Roumenina LT, Plantier JL, et al. A human FVIII inhibitor modulates FVII surface electrostatics at a VWF-binding site distant from its epitope. J Thromb Haemost. 2010

76. Matino D, Gargaro M, Santagostino E, et al IDO1 suppresses inhibitor development in hemophilia A treated with factor VIII. J Clin Invest. 2015;125(10):3766-3781.

77. Moghimi B, Sack BK, Nayak S, Markusic DM, Mah CS, Herzog RW. Induction of tolerance to factor VIII by transient co-administration with rapamycin. J Thromb Haemost. 2011;9(8):1524-1533.

78. Hassan S, Fijnvandraat K, van der Bom JG, Gouw SC. Preventing or eradicating factor VIII antibody formation in patients with hemophilia A: what can we learn from other disorders? Semin Thromb Hemost. 2018;44 (6):531-543.

79. Mahlangu J, Oldenburg J, Paz-Priel I, et al. Emicizumab prophylaxis in patients who have hemophilia A without inhibitors. N Engl J Med. 2018;379(9):811-822.

80. Oldenburg J, Mahlangu JN, Kim B, et al. Emicizumab prophylaxis in hemophilia A with inhibitors. N Engl J Med. 2017;377(9): 809-818. 